\title{
Assessing the Accuracy of Remotely Sensed Forest Maps for Nepal
}

\author{
Menaka Hamal, Rajesh Bahadur Thapa \\ menakahamal@gmail.com, rajesh.thapa@icimod.org
}

\section{KEYWORDS}

Remotely Sensed Maps, Point Sampling, Accuracy Assessment, Province wise Forest Coverage

\begin{abstract}
The accuracy assessment is vital to validate the remotely sensed thematic output before being front to the users. The statistical accuracy measures and modeling have been using widely for the accuracy assessment of the remote sensing product. This study uses six open-access land cover products - Land Cover of Nepal 2010, GlobeLand30, Treecover2010, Global PALSAR-2 forest/Non-Forest, Tree Canopy Cover (TCC), and ESACCI Land Cover 2010, to find out the most reliable forest product for Nepal. The forest/non-forest data were extracted from each product. The stratified random sampling was used to create test points and verified ground truth in Google Earth (GE) by visual interpretation. The overall accuracy (OA), producer's accuracy (PA), user's accuracy (UA), Kappa statistics, and the Nash-Sutcliffe model efficiency coefficient (NSE) were measured for each forest/non-forest map. The OA and UA were found to be highest by 94\%; the Kappa statistics showed an 89\% level of agreement and NSE showed $77 \%$ performance level for Nepal Land Cover 2010 which is the highest among six datasets. Whereas ESACCI land Cover 2010 was found to be the least performer $O A$ and $U A$ are $53 \%$ and $66 \%$ respectively, Kappa shows a 53\% level of agreement and NSE shows 4\%.. The ESACCI land Cover 2010 was found to be the highest coverage whereas Tree Canopy Cover (TCC) has the least one for each province. This study gives the methodological insight to compare remotely sensed datasets and help the user in the selection of the most reliable open-source forest map for Nepal.
\end{abstract}

\section{INTRODUCTION}

Forest resources play a vital role for the people and the planet by providing various goods and services (FAO 2018). However, according to Food and Agriculture Organization (FAO), $31.6 \%$ of the global forest area in 1990 reduced to $30.6 \%$ in 2015 mainly due to excessive use of fossil fuels and deforestation. With the access of satellite imageries and availability of image processing and interpretation tools, FAO started Global Forest Assessment to monitor forest resources using remote sensing since 1990 to maintain forest status and its change record at global, regional, and biome level. Likewise, different initiatives have developed land cover and thematic maps using satellite imageries that capture from different sensors, following scientific and methodological processes and techniques, and made them available to the public. To select and use the 
most reliable products in a specific area, the remotely sensed maps are compared.

The various studies regarding the comparison of remotely sensed maps have been conducted globally. However, limited to some of the countries. (Estoque et al., 2018) assessed and compared eight remotely sensed forest maps for Philippine and concluded that NAMRIA30 had the lowest overall dis-agreement with the reference data whereas GLOBELAND30 had the highest. Similarly, (Yang et al., 2017) compared eight forest products with a medium resolution $(30-50 \mathrm{~m})$ imagery for China and found that the forest areas of OU-FDL and JAXA forest maps had a high correlation with that of GlobeLand30. Likewise, (Bai et al., 2014) compared five global land cover datasets for China to look into the consistencies and discrepancies among those datasets. (Giri, Zhu, \& Reed 2005) compared the Global Land Cover 2000 and MODIS global land cover data to evaluate the similarities and differences in methodologies, and identified the areas of spatial agreement and disagreement among datasets. This comparison makes users be informed before the selection of land cover data required for the specific applications.

In Nepal, forest occupies 5.96 million ha $(40.36 \%)$, forest including woodland covers $44.74 \%$ of the total area of the country (DFRS 2015).. So, Department of Forest and Research Survey (DFRS) has been generated forest and land cover datasets as a part of the forest inventories, but those are closed source. The national-level open-source land cover dataset for the year 2010 acquired from the International Center for Integrated Mountain Development (ICIMOD).

The global land cover and thematic datasets are also available free from the web such as GlobeLand30 - land cover global raster dataset developed by the National Geomatics
Center of China, Global tree cover data (treecover2010) developed by University of Maryland, Global $25 \mathrm{~m}$ resolutions PALSAR-2/PALSAR mosaic and forest/nonforest map prepared by Earth Observation Research Center (EORC) of Japan Aerospace Exploration Agency (JAXA), Tree Canopy Cover (TCC) layers by the USA, ESACCI Land Cover 2010 generated by Climate Change Initiative (CCI) of European Space Agency (ESA) and Nepal Land Cover 2010 map created by ICIMOD.

The accuracy of remote sensing thematic data should be known before the application of a product to the intended application (Rwanga\&Ndambuki, 2017). The accuracy measurement is an essential procedure that has been followed to check the reliability of the thematic output (Foody, 2002). During the assessing process, the classified thematic categories of the image are verified to the same categories of the reference image (Anand, 2017). The reference data has been generated by applying the appropriate sampling technique or points/pixels are manually generated in the reference image or collect ground truth points visiting the study area to verify with the classified points/ pixels. Then, the reference data have been verified with the position of the object of the classified image or vice versa (UoT, 2021). The verified data run through the statistical accuracy measures - the most common measures are the confusion matrix for finding out the performance of a classification model, and the Kappa statistics to measure the level of agreement (Foody, 2010). This study follows the point sampling method where sample points are generated using a stratified random sampling technique. The forest and non-forest classes are taken as strata in which the points are allocated randomly. The allocated points are verified with the original image to compute the confusion matrix and kappa statistics for 
finding out the reliability of the classified map. This study addresses the selection of the most reliable open-source national as well as the global dataset and gives the methodological insight to compare the remotely sensed forest maps for Nepal.

\section{METHODOLOGY}

\subsection{Study Area}

Nepal was taken as a study area for assessing the accuracy of forest maps. The country is situated between China in the North; and India in the east, west, and south with latitude $26^{\circ}$ $22^{\prime} \mathrm{N}$ to $30^{\circ} 27^{\prime} \mathrm{N}$ and longitudes $80^{\circ} 04 \mathrm{E}$ to $88^{\circ} 12^{\prime}$ E.. It expands approximately $885 \mathrm{~km}$ from east to west, and widens about $130 \mathrm{~km}$ to $260 \mathrm{~km}$ north-south with elevation starts from approximately 60 meters from the tropical Terai to the highest 8,848.86 meters peak of the World Mt. Sagarmatha (DFRS, 2015). The forest area varies across the physiographic regions that start from low land in the south to the mountainous reason in the north. Out of $40.36 \%$ of the total area of the country's forest, $20.4 \%$ lies in the Terai region, $72.4 \%$ in Churia, $52.3 \%$ in Middle Mountain, and $29.4 \%$ in High Mountain and High Hamal (DFRS, 2016).

\subsection{Methodological Flow Chart}

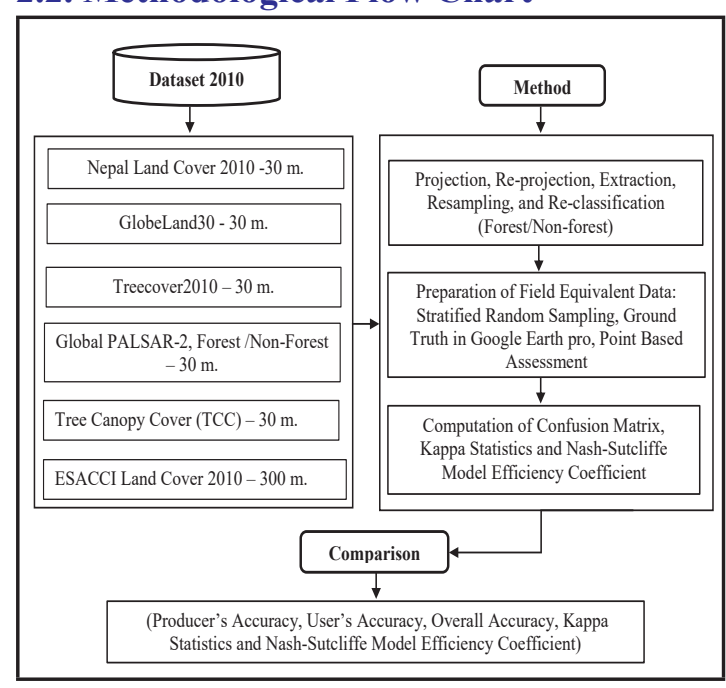

Figure 1: Process flow chart
The flow chart depicts the raster analysis techniques used for the computation of statistical accuracy measures as well as their comparison (Figure 1).

\subsection{Data, Classification, and Reclassification}

The six forest/non-forest maps were extracted from remotely sensed open-source land cover products of 2010. One is a national LULC product and the others are global coverage. (Table 1). These products were downloaded from the websites of the respective initiatives. Those data were projected, and re-projected to GCS_WGS_1984 to bring different them into a common coordinate system and reference frame Then, the cells were extracted with the administrative boundary of Nepal and resampled to $30 \times 30$ meters each datum to make cell size consistent.

The dataset had their own classification system. Some were given in classes and some were in values in the attribute table. Those original classes and values of each dataset were reclassified into the forest, and the non-forest classes according to the classified thematic coverage and given raster values of the respective dataset. The eight categories of Nepal Land Cover 2010 data of ICIMOD have been reclassified into two strata - Forest and Non-Forest. Similarly, GloveLand30 data of China reduced to two strata. The TCC 2010and ESACCI Land Cover 2010 dataset, the original values of the dataset were reviewed and reclassified into two classes. The Global PALSAR-2, Forest/Non-Forest dataset was directly extracted (Table 1). 
Table 1: Data source, resolution, and classification of the datasets

\begin{tabular}{|c|c|c|c|c|c|c|}
\hline Data & Reference & $\begin{array}{c}\text { Satellite } \\
\text { Data Source }\end{array}$ & $\begin{array}{c}\text { Spatiotemporal } \\
\text { Reso. }\end{array}$ & $\begin{array}{c}\text { Classification } \\
\text { Technique }\end{array}$ & $\begin{array}{c}\text { Original data } \\
\text { classification/values }\end{array}$ & $\begin{array}{c}\text { Reclassification to } \\
\text { Forest and Non- } \\
\text { Forest for this } \\
\text { study }\end{array}$ \\
\hline $\begin{array}{l}\text { Nepal Land } \\
\text { Cover } 2010\end{array}$ & $\begin{array}{l}\text { (ICIMOD } \\
2010)\end{array}$ & Landsat TM & $\begin{array}{l}30 \mathrm{~m} . \\
2010\end{array}$ & $\begin{array}{l}\text { Object Based } \\
\text { Classification }\end{array}$ & \begin{tabular}{|lr} 
F o r e s t , s h r u b l a nd, \\
grassland, \\
barren area, \\
snow/glacilture, body, \\
area
\end{tabular} & $\begin{array}{l}\text { Forest and Non- } \\
\text { forest (other than } \\
\text { forest) }\end{array}$ \\
\hline $\begin{array}{l}\text { Gloebe Land } \\
30\end{array}$ & $\begin{array}{l}\text { (NGCC, } \\
2014)\end{array}$ & \begin{tabular}{|l|} 
Landsat TM5 \\
and ETM +
\end{tabular} & $\begin{array}{l}30 \mathrm{~m} . \\
2010\end{array}$ & $\begin{array}{l}\text { pixel-object- } \\
\text { knowledge based } \\
\text { method }\end{array}$ & $\begin{array}{l}\text { 10: Cultivated land, } \\
\text { Forest, Grassland, } \\
\text { Shrubland, Water bodies, } \\
\text { Wetland, Tundra, Artificial } \\
\text { surfaces, Bareland, } \\
\text { Permanent snow and ice }\end{array}$ & $\begin{array}{l}\text { Forest: } r \text { Lands } \\
\text { covered with trees, } \\
\text { with vegetation } \\
\text { cover over } 30 \% \text {, } \\
\text { including deciduous } \\
\text { and coniferous } \\
\text { forests, and sparse } \\
\text { woodland with } \\
\text { cover } 10-30 \% \text { and } \\
\text { other non-forest. }\end{array}$ \\
\hline Treecover 2010 & $\begin{array}{l}\text { (Hansen et al } \\
2013 \text { ) }\end{array}$ & $\begin{array}{l}\text { Landsat } 7 \\
\text { ETM }+\end{array}$ & $\begin{array}{l}30 \mathrm{~m} . \\
2010\end{array}$ & $\begin{array}{l}\text { Decision tree } \\
\text { classification }\end{array}$ & $\begin{array}{l}\text { The resulting layer } \\
\text { represents estimated } \\
\text { maximum tree canopy } \\
\text { cover per pixel, } 1-100 \% \\
\text { for the year 2010 in } \\
\text { integer values }(1-100) \text {. }\end{array}$ & $\begin{array}{l}\text { integer values } \\
100) \text { and excluded } \\
\text { other values }\end{array}$ \\
\hline $\begin{array}{l}\text { Global } \\
\text { PALSAR-2, } \\
\text { Forest /Non- } \\
\text { Forest }\end{array}$ & $\begin{array}{l}\text { (EORC, } \\
2019)\end{array}$ & $\begin{array}{l}\text { PALSAR } \\
\text { and } \\
\text { PALSAR-2 }\end{array}$ & $25 \mathrm{~m}$. & $\begin{array}{l}\text { SAR processing } \\
\text { algorithm: Sigma- } \\
\text { SAR IMAGE } \\
\text { and Sigma-SAR } \\
\text { MOSAIC } \\
\end{array}$ & $\begin{array}{l}\text { classified "forest" (colored } \\
\text { in green) and "non-forest" } \\
\text { (colored in yellow) }\end{array}$ & $\begin{array}{l}\text { classified "forest" } \\
\text { (colored in green) }\end{array}$ \\
\hline $\begin{array}{l}\text { Tree Canopy } \\
\text { Cover (TCC) }\end{array}$ & $\begin{array}{l}\text { (Sexton et al } \\
2013)\end{array}$ & Landsat & $\begin{array}{l}30 \mathrm{~m} . \\
2010\end{array}$ & $\begin{array}{l}\text { Regression Tree } \\
\text { Model }\end{array}$ & \begin{tabular}{|l}
38 classified values with \\
different categories of land \\
cover such as cropland, \\
tree cover, shrubland, \\
grassland, lichen mosses, \\
sparse vegetation, urban \\
areas, water bodies, \\
prominent snow and ice \\
(Values from 0 to 220) \\
\end{tabular} & $\begin{array}{l}\text { The tree cover } \\
\text { categories such as } \\
\text { mosaic cropland } \\
\text { and ratural } \\
\text { vegetation, tree } \\
\text { cover broadleaved, } \\
\text { evergreen } \\
\text { deciduous, closed/ } \\
\text { open, closed to } \\
\text { open and needle- } \\
\text { leaved deciduous/ } \\
\text { evergreen, open/ } \\
\text { closed, closed to } \\
\text { open and mixed leaf } \\
\text { type (Value 12 and } \\
30 \text { to 90) }\end{array}$ \\
\hline $\begin{array}{l}\text { ESACCI Land } \\
\text { Cover } 2010\end{array}$ & $\begin{array}{l}\text { (ESA-CCI } \\
2017)\end{array}$ & MERIS & $\begin{array}{l}300 \mathrm{~m} . \\
2010\end{array}$ & $\begin{array}{l}\text { Unsupervised } \\
\text { classification chain } \\
\text { with machine } \\
\text { learning algorithm }\end{array}$ & \begin{tabular}{|l} 
\\
38 classified values with \\
different categories of land \\
cover such as cropland, \\
tree cover, shrubland, \\
grassland, lichen mosses, \\
sparse vegetation, urban \\
areas, water bodies, \\
prominent snow and ice \\
\end{tabular} & $\begin{array}{l}\text { The tree cover } \\
\text { categories such as } \\
\text { mosaic cropland } \\
\text { and natural } \\
\text { vegetation, tree } \\
\text { cover broadleaved, } \\
\text { e v e r g r e e n / } \\
\text { deciduous, closed/ } \\
\text { open, closed to } \\
\text { open and needle- } \\
\text { leaved deciduous/ } \\
\text { evergreen, open/ } \\
\text { closed, closed to } \\
\text { open and mixed leaf } \\
\text { type (Value } 30 \text { to } 90, \\
100,110,150)\end{array}$ \\
\hline
\end{tabular}




\subsection{Preparing Field Equivalent Data}

The field equivalent data is crucial for the accuracy assessment (Thomas, 2015). For that, the spatial support unit is taken to compare the locations of classified maps to the reference maps for validation (FAO, 2020). If the study area is large and physically inaccessible, the pixels or points can be a common choice of the assessment unit (Stahman, 2009). The point assessment strategy was implemented in this study. The required sample size was calculated using a sample size calculatoronline (https://www.checkmarket.com/sample-sizecalculator/). For that, the area of Nepal was taken with a $95 \%$ confidence level and 3\% set as a confidence interval, which suggests that 1060 samples are required to achieve the desired level of precision. After determining the sample size, a random stratified sampling method was adopted to prepare the reference data using Sampling Design Tool in ArcGIS. This method allocates the sample size for each land cover category based on the spatial extent, and eliminating class level bias (Stehman, 2009). The classified and ground truth columns were created in the attribute table so that the classified points can be verified with the reference data (ESRI 2020).

The reference data source was Google Earth due to the availability of possible highresolution imageries and a cost-effective source of spatial information (Ragheb \& Ragab, 2015). This platform has been used to verify the multi-temporal land cover classification where the study area is physically inaccessible (Cha \& Park 2007). Olofsson et al., 2020 stressed that the "reference data should be of higher quality than the data used for creating the map" therefore the GE platform was used to verify the points. For that, the generated points of classified maps were overlayed on GE and check whether each pixel covers the forest area or not for the year 2010 with visual interpretation. When the reference points were not clear due to unclear images, incomplete coverage, and dense clouds on GE for the year 2010, the points were verified by taking the reference imageries of the year 2008 to 2012. Every verified point on GE was edited as the ground truth field of the attribute table to use data to compute the confusion matrix.

\subsection{Analytical Approach for Comparison}

The classification model performance was tested for each forest/non-forest map by computing the confusion matrix based on the values of verified pixels of classified maps to the ground truth points on GE. By evaluating the records of the confusion matrix, the producer's accuracy that relates to the map makers and error of omission was computed by taking the ratio of the number of reference sites classified accurately to the total number of reference sites for that class. Similarly, the user's accuracy that relates to the map users and error of commission - the ratio of correctly classified sites to the total number of classified sites (GPS216, 2019), was calculated. Likewise, the overall accuracy was accessed based on the number of correctly classified pixels and the total number of pixels used for accuracy assessment. The omission error was found by reviewing the incorrect classified pixels of reference sites and computed by taking the ratio of the number of incorrectly classified pixels and the total number of reference sites for each class. The large omission errors show that the large difference between the mapped area and the real area. The real land cover type is left out or omitted from the classified map (Olofsson et al 2020). Then, the commission error was calculated by reviewing the incorrect classified pixels of the classified site and calculated as the ratio of incorrectly classified sites and the total number of classified sites for each class.

The kappa coefficient is one of the commonly used statistics to test the degree of agreement by chance (Mchugh, 2012). The values range from 0 to 1 ; where 0 interprets no agreement 
between the classified and reference images and 1 gives the identical of classified images and ground truth images (Cohen, 1960).. The level of the agreement depends on the value of Kappa that gives the percentage reliability of the data. The value 0 to 0.20 gives the $0-4 \%$ reliability that interprets no agreement, 0.21 to 0.39 gives $4-15 \%$ reliability with the minimal agreement, 0.40 to 0.59 gives 15 $35 \%$ reliability that interprets the weak level of agreement, 0.60 to 0.79 gives $35-63 \%$ reliability with the moderate agreement, 0.80 to 0.90 gives $64-81 \%$ reliability interprets the strong level of agreement and bove 0.90 gives $82-100 \%$ that interprets the almost perfect level of agreement (Mchugh, 2012). To test the degree of reliability of each map, the Kappa statistics were computed.

The Nash-Sutcliffe Model Efficiency Coefficient (NSE) was calculated to determine the model performance of each dataset by taking the number of pixels of the classified map and the number of verified pixels. It gives how well the observed versus simulated data fits the 1:1 line. NSE model output ranges from -1 to 1 . If the calculated value closer to 1 , the model would be more accurate (Agrimetsoft, 2020). NSE was computed using an online calculator of agricultural and metrological software -https://agrimetsoft.com/ calculators/Nash $\% 20$ Sutcliffe $\% 20$ model $\% 20$ Efficiency\%20coefficient. This online software was modeled with the classified points and the verified ground truth points to get the actual NSE value.

\section{RESULT AND DISCUSSION}

The image classification process always demands the accuracy of thematic maps before being front to the users. The assessment output may vary from application to application but need to rely on the resulted quantitative output to know the map reliability (Thomas et al., 2015). Table 2 provides a summary of the outputs of a quantitative assessment - OA,
PA, and UA.The degree of similarity in spatial patterns between the classified map and the reference data.

For the forest and non-forest map of the Land Cover of Nepal 2010, out of 1060 pixels, a total of 1001 are correctly classified (411 as forest and 590 as non-forest). The OA value is 0.94 which means the classified image has $94 \%$ accuracy that conveys the $6 \%$ error in the overall image. The matrix shows that the 26 forest pixels and 33 non-forest pixels are found to be miss-classified. The calculated omission error (OE) for the forest becomes 7 with the commission error (CE) 5. For the non-forest, the $\mathrm{OE}$ is 4 and the $\mathrm{CE}$ becomes 6 . The PA for non-forest is $96 \%$ whereas $84 \%$ forthe forest. The UA $95 \%$ for non-forest and $94 \%$ in the forest.Similarly, the GlobeLand30 has 921 correctly classified pixels (374 forests and 547 non-forest) so OA becomes $87 \%$ that notified the $13 \%$ overall error. The 70 forest pixels and 69 non-forest pixels are found to be missclassified. The OE is 16 and CE 11 for forest and the value becomesreverse in non-forest errors. PA is 84 for forest and 89 for non-forest that is similar to UA as it reflects that there is no conflict between map user and producer. Likewise, for the Treecover2010, the total 917 correctly classified pixels so OA becomes $87 \%$ that is similar to the OA of GlobeLand 30 . The PA is $80 \%$ for forest and 92 for non-forest but the UA for the forest is 87 . The 91 forest pixels and 52 non-forest pixels are found to be miss-classified. The OE and CE for the forest are 20 and 14 respectively, and for the nonforest 8 and 13 respectively. The OA of Global PALSAR-2, Forest /Non-Forest is $80 \%$ which is quite less than the previous maps and has a $20 \%$ overall error. The PA is 76 for the forest and 82 for the non-forest whereas UA 75 for the forest and 83 for the non-forest. OE and $\mathrm{CE}$ are 24 and 17 respectively for forest and 18 and 25 for non-forest. Also, The Tree Canopy Cover (TCC) map has OA and error is similar to PALAR-2 but the OE and CE are quite high 
for forest ie. 35 and 22 respectively and nonforest ie. 10 and 17 respectively. The PA 95 and 90 and UA 83 and 78 for forest and non-forest respectively. Then, the ESACCI Land Cover 2010has the lowest OA i.e. 76\%, and highest error i.e. $24 \%$ among other maps.

Table 2: Statistics of accuracy assessment

\begin{tabular}{|c|c|c|c|c|c|}
\hline Dataset & ClassValue & Non-forest & Forest & Total & UA \\
\hline \multirow{4}{*}{$\begin{array}{l}\text { Land Cover of } \\
\text { Nepal } 2010\end{array}$} & Non-forest & 590 & 33 & 623 & 0.95 \\
\hline & Forest & 26 & 411 & 437 & 0.94 \\
\hline & Total & 616 & 444 & 1060 & \\
\hline & PA & 0.96 & 0.93 & & $\mathrm{OA}=0.94$ \\
\hline \multirow{4}{*}{ GlobeLand30 } & Non-forest & 547 & 70 & 617 & 0.89 \\
\hline & Forest & 69 & 374 & 443 & 0.84 \\
\hline & Total & 616 & 444 & 1060 & \\
\hline & PA & 0.89 & 0.84 & & $\mathrm{OA}=0.87$ \\
\hline \multirow{4}{*}{ Treecover2010 } & Non-forest & 564 & 91 & 655 & 0.86 \\
\hline & Forest & 52 & 353 & 405 & 0.87 \\
\hline & Total & 616 & 444 & 1060 & \\
\hline & PA & 0.92 & 0.80 & & $\mathrm{OA}=0.87$ \\
\hline \multirow{4}{*}{$\begin{array}{l}\text { Global PALSAR-2, } \\
\text { Forest /Non-Forest }\end{array}$} & Non-forest & 506 & 106 & 612 & 0.83 \\
\hline & Forest & 110 & 338 & 448 & 0.75 \\
\hline & Total & 616 & 444 & 1060 & \\
\hline & PA & 0.82 & 0.76 & 0.00 & $\mathrm{OA}=0.80$ \\
\hline \multirow{4}{*}{$\begin{array}{l}\text { Tree Canopy Cover } \\
\text { (TCC) }\end{array}$} & Non-forest & 555 & 154 & 709 & 0.78 \\
\hline & Forest & 61 & 290 & 351 & 0.83 \\
\hline & Total & 616 & 444 & 1060 & \\
\hline & PA & 0.90 & 0.65 & & $\mathrm{OA}=0.80$ \\
\hline \multirow{4}{*}{$\begin{array}{l}\text { ESACCI Land } \\
\text { Cover } 2010\end{array}$} & Non-forest & 420 & 57 & 477 & 0.88 \\
\hline & Forest & 196 & 387 & 583 & 0.66 \\
\hline & Total & 616 & 444 & 1060 & \\
\hline & PA & 0.68 & 0.87 & & $\mathrm{OA}=0.76$ \\
\hline
\end{tabular}

Only OA is not sufficient to measure the accuracy so the Kappa coefficient was tested as it is a common statistical measure of agreement (Mchugh, 2012). Figure 2 shows that the Land cover of Nepal 2010 has a strong level of agreement as the value of it lies between 0.080.90 that gives $64-81 \%$ reliability of the map. Similarly, the statistics of The GlobeLand30 and Treecover2010 lie between 0.60 and 0.79 give $35-63 \%$ reliability and havea moderate level of agreement. TheGlobal PALSAR-2 Forest /Non-Forest, Tree Canopy Cover (TCC), and ESACCI Land Cover 2010 have values range from 0.52 to 0.57 those have reliability comes between $15 \%$ to $35 \%$ that interprets the weak level of agreement.

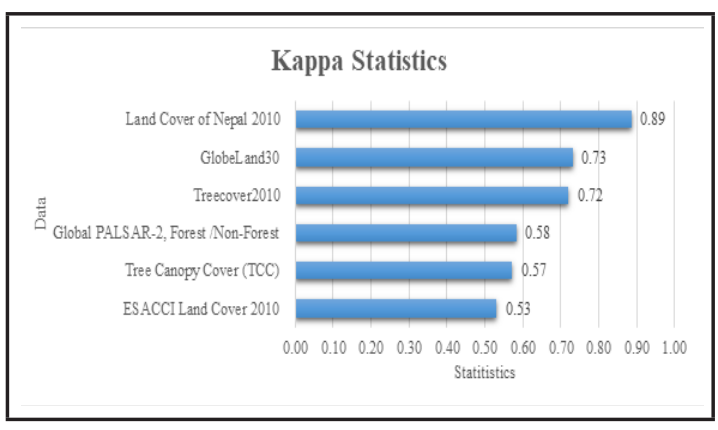

Figure 2: Kappa statistics

The NSE, the model performance indicator gives the coefficient that can be used to find the model performance for each dataset. Table 3 shows that the NSE coefficients for each dataset range from 0.04 to 0.77 . The Land Cover of Nepal 2010 has the highest which means the number of pixels of the classified 
map and the number of reference data has a $77 \%$ approximate similarity. Then the secondhighest performer becomes GlobeLand30 that has $71 \%$ followed by Treecover2010, Global PALSAR-2, Forest /Non-Forest 43\%, and $17 \%$ respectively. The ESACCI Land Cover 2010 is the least performer ie $4 \%$ followed by Tree Canopy Cover (TCC) ie $8 \%$.

Table 3: Nash-Sutcliffe model efficiency coefficient

\begin{tabular}{|l|c|}
\hline \multicolumn{1}{|c|}{ Dataset } & NSE \\
\hline Land Cover of Nepal 2010 & 0.77 \\
\hline GlobeLand30 & 0.71 \\
\hline Treecover2010 & 0.43 \\
\hline Global PALSAR-2, Forest /Non-Forest & 0.17 \\
\hline Tree Canopy Cover (TCC) & 0.08 \\
\hline ESACCI Land Cover 2010 & 0.04 \\
\hline
\end{tabular}

Fig. 3 shows that the percentage forest coverage of each dataset for seven provinces of Nepal. The extracted forest cover from ESACCI Land Cover 2010 has the highest forest coverage for each province followed by The Global PALAAR-2, Forest/Non-Forest, and TCC.

In Province 1, 58\% forest for ESACCI Land Cover 2010 followed by Global PALSAR-2 (46.7\%), Nepal Land cover 2010 (45.5\%), GlovbeLand30 (45.1), Treecover2010 (39.3\%) whereas least TCC ( $33.1 \%$ ) forest coverage. Similarly, in Province 2, the highest ie $26.9 \%$ forest of the Nepal Land Cover 2010 followed by Globland30 and Treecover2010 (24.6\%), the Global PALSAR-2 (22.9\%), TCC (20.4 \%) whereas the least ESACCI Land Cover 2010 (20.1\%). In Bagmati Province, 72.4\% i.e. highest forest coverage of ESACCI Land Cover 2010 followed by Treecover 2010 (53.8\%), Nepal Land Cover 2010 (53.7\%), Global PALSAr-2 (49.5\%), GlobeLand30 $(42.8 \%)$ and the least coverage TCC (38.7\%). In Gandaki Province, the highest forest coverage is $52.2 \%$ of ESACCI Land Cover 2010 followed by Global PALASR (41.3\%), GlobeLand30 (33.3\%), Nepal Land Cover
2010 (32\%), and the TCC and Treecover2010 has $28.2 \%$ coverage. In Lumbini Province, the highest forest coverage is ESACCI Land Cover 2010 i.e. $59.2 \%$ whereas the lowest is TCC i.e. $33.1 \%$. The GlobeLand 30 has $51.5 \%$ i.e. second highest followed by $50.6 \%$, $48.3 \%$ and 47.5 for Treecover2010, Nepal Land Cover 2010, and Global PALSAR-2 respectively. InKarnali Province, the ESACCI has highest forest coveragei.e. $45.3 \%$ whereas the lowest is $20.8 \%$ for TCC. The $36.9 \%$ for Global PALSAR-2, 34.2\% for GlobeLand30, 29.6\% for Nepal Land Cover 2010 and $24.2 \%$ for Treecover 2010 forest coverage. SudurpashimProvincehas the second highest forest coverage i.e. $61.6 \%$ coverage for ESACCI Land Cover 2010 as compared to other products. The Nepal Land Cover 2010 has $51.6 \%$ followed by $49.7 \%$ of Global PaLSAR-2, 48\% of GlobeLand30, $46.1 \%$ of Treecover 2010 , and the least one is $36.6 \%$ of TCC. All over, Province 2 has the lowest forest coverage followed by Karnali Province and Gandaki Province whereas SudurpashimProvince has the highest followed by Province 1, Lumbini, and Bagmati.

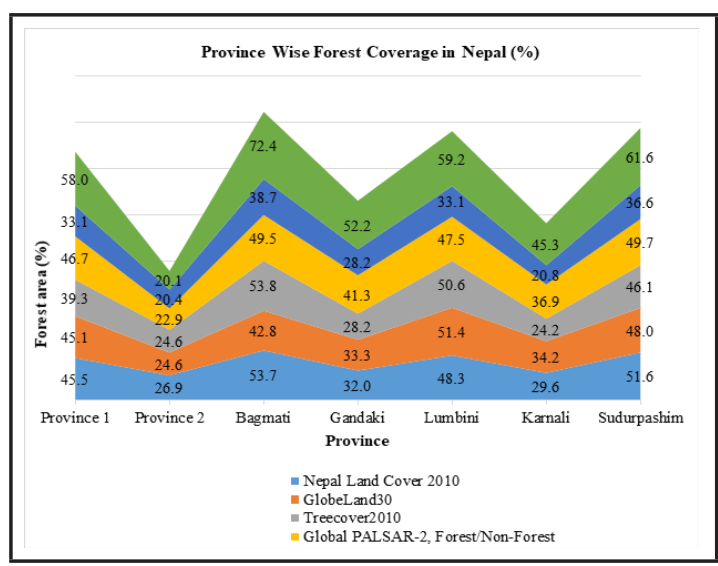

Figure 3: Province wise forest coverage in Nepal

Figure 4 shows the maps of the forest that shaded as leafy green and non-forest that shaded in Sahara sand color, of Bagmati Provinceof Nepal. The forest coverage observed highest in ESACCI Land Cover 2010 
whereas it found to be lowest in Tree Canopy Cover (TCC) among six maps.

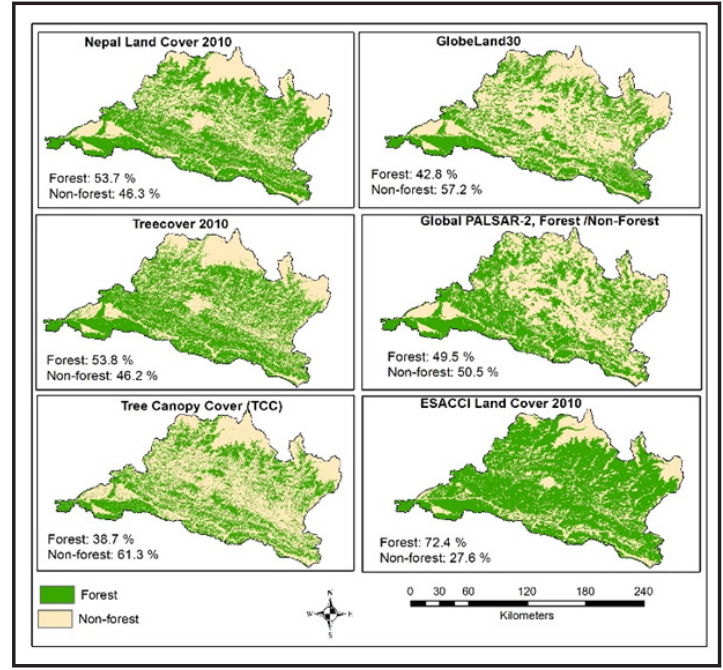

Figure 4: Forest and Non-Forest Coverage of Bagmati Province

\section{CONCLUSION}

The remotely sensed land resource maps have been prepared using satellite imageries and made those publically available through the different initiatives expecting further use from local to a global scale. The required natural resource coverage can be extracted from those open source thematic maps. The six open-source forest cover maps for the year 2010 were extracted to compare which one is the most reliable for Nepal.. The stratified random sampling was used to create 1060 points to compute accuracy from classified and reference data. The reference data generated from GEhigh-resolution imagery by visual interpretation and validated classified pixels with ground truth for each dataset. Among the six datasets, the forest/ non-forest data of Land Cover Nepal 2010 has the highest OA (94\%) whereas it is lowest $(53 \%)$ in ESACCI Land Cover 2010. The GlobeLand30, Treecover2010, Global PALSAR-2Forest/Non-Forest, and TCC were found to be accurate by $87 \%, 86.5 \%, 80 \%$, and $79.7 \%$ respectively. The Land cover of Nepal 2010 has the highest UA (94\%) whereas the lowest (66\%) in ESACCI Land Cover 2010 as compared to other maps. The GlobeLand30, Treecover2010, Global PALSAR-2, Forest / Non-Forest and TCC has $84 \%, 87 \%, 75 \%$ and $83 \%$ UA respectively. The kappa statistics of the Land Cover of Nepal 2010 have 0.89 value which shows a strong level of agreement whereas Global PALSAR-2_Forest /NonForest map, TCC, and ESACCI 0.58, 0.57, and 0.53 respectively has a weak level of agreement. The GlobeLand30 has 0.73 and Treecover 2010 has 0.72 that shows reliability with a moderate level of agreement. The NSE model has performed best with the Land Cover of Nepal 2010 that has by $77 \%$ of approximate similarity to the pixels of classified maps with the reference map. This study would help users on map selection for forest resource monitoring and give methodological insight to compare remotely sensed forest maps for Nepal.

\section{REFERENCE}

Agrimetsoft, (2020). Nash Sutcliffe model efficiency coefficient. Agricultural and Meteorological software.

https://agrimetsoft.com/calculators/Nash $\% 20$ Sutcliffe $\% 20$ model $\% 20$ Efficiency $\% 20$ $\underline{\text { coefficient }}$

Anand,A.(2017). Unit14AccuracyAssessment. (January 2017), 59-77. Retrieved from https://www.researchgate.net/ publication/324943246 UNIT 14 ACCURACY ASSESSMENTBai, Y., Feng, M., Jiang, H., Wang, J., Zhu, Y., \& Liu, Y. (2014). Assessing consistency of five global land cover data sets in China. Remote Sensing, 6(9), 8755. https://doi.org/10.3390/rs6098739

Cha, S. and Park, C. (2007). The Utilization of Google Earth Images as Reference Data for the Multitemporal Land Cover Classification with MODIS Data of North Korea. Graduate School of Environmental Studies, Seoul National University, Korea 
Cohen, J. (1960). A COFFICIENT OF AGREEMENT FOR NORMAL SCALES. XX(1), 37-46. https://doi. org $/ 10.1177 / 001316446002000104$

DFRS, (2015). State of Nepal's Forests. Forest Resource Assessment (FRA) Nepal, Department of Forest Research and Survey. Kathmandu, Nepal.

DFRS. (2016). Forest Resource Assessment Nepal. Department of Forest Research and Survey. Kathmandu, Nepal.http:// www.dfrs.gov.np/downloadfile/main result 1470141289.pdf

EORC, (2019). Global 25m Resolutions PALSAR-2/PALSAR Mosaic and Forest/Non-Forest. Earth Observation Research Center.Japan Aerospace Exploration Agency. https://www.eorc. jaxa.jp/ALOS/en/palsar fnf/fnf index. $\underline{\mathrm{htm} \# \text { description }}$

ESA-CCI, (2017). The Land Cover CCI Climate Research Data Package $(C R D P)$. European Space Agency Climate Change Initiative. http://maps. elie.ucl.ac.be/CCI/viewer/download. php

ESRI, (2020). Understanding of Segmentation and Classification. https://pro.arcgis. com/en/pro-app/tool-reference/spatialanalyst/understanding-segmentationand-classification.htm

Estoque, R. C., Pontius, R. G., Murayama, Y., Hou, H., Thapa, R. B., Lasco, R. D., \&Villar, M. A. (2018). Simultaneous comparison and assessment of eight remotely sensed maps of Philippine forests. International Journal of Applied Earth Observation and Geoinformation, 67(January 2017), 289. https://doi. org/10.1016/j.jag.2017.10.008

FAO, (2018). Time is running out for the world's forests: total area is shrinking by the day. Food and Agriculture Organization. http://www.fao.org/ americas/noticias/ver/en/c/1144234/
FAO, (2020). Global Forest Resources Assessment 2020. https://doi. org/10.4060/ca8753en

Foody, G. M. (2002). Status of land cover classification accuracy assessment. Remote Sensing of Environment, 80(1), 185-201. $\quad$ https://doi.org/10.1016/ S0034-4257(01)00295-4

Foody, G. (2010). Assessing the Accuracy of Remotely Sensed Data: Principles and Practices. In The Photogrammetric Record (Vol. 25). https://doi.org/1 0.1111/j.1477-9730.2010.00574_2. xGiri, C., Zhu, Z., \& Reed, B. (2005). A comparative analysis of the Global Land Cover 2000 and MODIS land cover data sets. Remote Sensing of Environment, 94(1), 131. https://doi. org/10.1016/j.rse.2004.09.005

GPS216, (2019). Introduction to Remote Sensing. Accuracy Matrix. http:// gis.humboldt.edu/OLM/Courses/ GSP 216 Online/lesson6-2/metrics. html

Hansen, M.C., Potapov, P.V., Moore, R., Hancher, M., Turubanova, S.A., Tyukavina, A., Thau, D., Stehman, S.V., Goetz, S.J., Loveland, T.R., Kommareddy, A., Egorov, A., Chini, L., Justice, C.O., and Townshend, J.R.G. (2013). High-Resolution Global Maps of 21st-Century Forest Cover Change: Science, v. 342, no. 6160, p. 50-853. http://www.sciencemag.org/ content/342/6160/850.abstract

Mchugh, M. L. (2012). Lessons in biostatistics Interpreter reliability: the kappa statistic. 276-282. https://doi. org/10.11613/BM.2012.031

Ragheb, A. E., \& Ragab, A. F. (2015). Enhancement of Google Earth Positional Accuracy. International Journal of Engineering Research and Technology, 4(1), 627-630.

Sexton, J. O., Song, X.-P., Feng, M., Noojipady, P., Anand, A., Huang, C., Kim, D.-H., 
Collins, K.M., Channan, S., DiMiceli, C., Townshend, J.R.G. (2013). Global, 30-m resolution continuous fields of tree cover: Landsat-based rescaling of MODIS Vegetation Continuous Fields with lidar-based estimates of error. International Journal of Digital Earth, 130321031236007. doi:10.1080 /17538947.2013.786146. https://data. fs.usda.gov/geodata/rastergateway/ treecanopycover/

ICIMOD. (2010). Land cover of Nepal 2010 [Data set]. ICIMOD. https://doi. org $/ 10.26066 /$ rds. 9224

Kandel, P. (2010). Forest resource assessment in Nepal: an assessment of data needs. http://www. forestrynepal.org/images/publications/ Data\%7B \%7Dneeds\%7B \%7Dfinal. pdf

NGCC (2014). 30-meter global land cover dataset (GlobeLand30): product description. National Geometrics Center of China. Retrieved from http:// www.globallandcover.com/home/ Enbackground.aspx (accessed 29. 09.19).

Olofsson, P., Arévalo, P., Espejo, A. B., Green, C., Lindquist, E., Mcroberts, R. E., \&Sanz, M. J. (2020). Remote
Sensing of Environment Mitigating the effects of omission errors on area and area change estimates.Remote Sensing of Environment, 236(January 2019), 111492. https://doi.org/10.1016/j. $\underline{\text { rse. } 2019.111492}$

Rwanga, S. S., \& Ndambuki, J. M. (2017). Accuracy Assessment of Land Use / Land Cover

Stehman, S. V. (2009). Sampling designs for accuracy assessment of land cover. International Journal of Remote Sensing, 30(20), 5243-5272. https:// doi.org/10.1080/01431160903131000

Thomas M. Lillesand, Ralpha W. Kiefer, J. W. C. (2015). Remote Sensing and Image Interpretation (Seventh Ed).

UoT, (2021). 15 - Data quality: quality assessment. University of Twente, Netherland. Retrieved from https://ltb. itc.utwente.nl/498/learningoutcome/ show/59281

Yang, Z., Dong, J., Liu, J., Zhai, J., Kuang, W., Zhao, G., ... Xiao, X. (2017). Accuracy assessment and intercomparison of eight medium resolution forest products on the loess plateau, China. ISPRS International Journal of Geo-Information, 6(5), 15. https://doi. org/10.3390/ijgi6050152

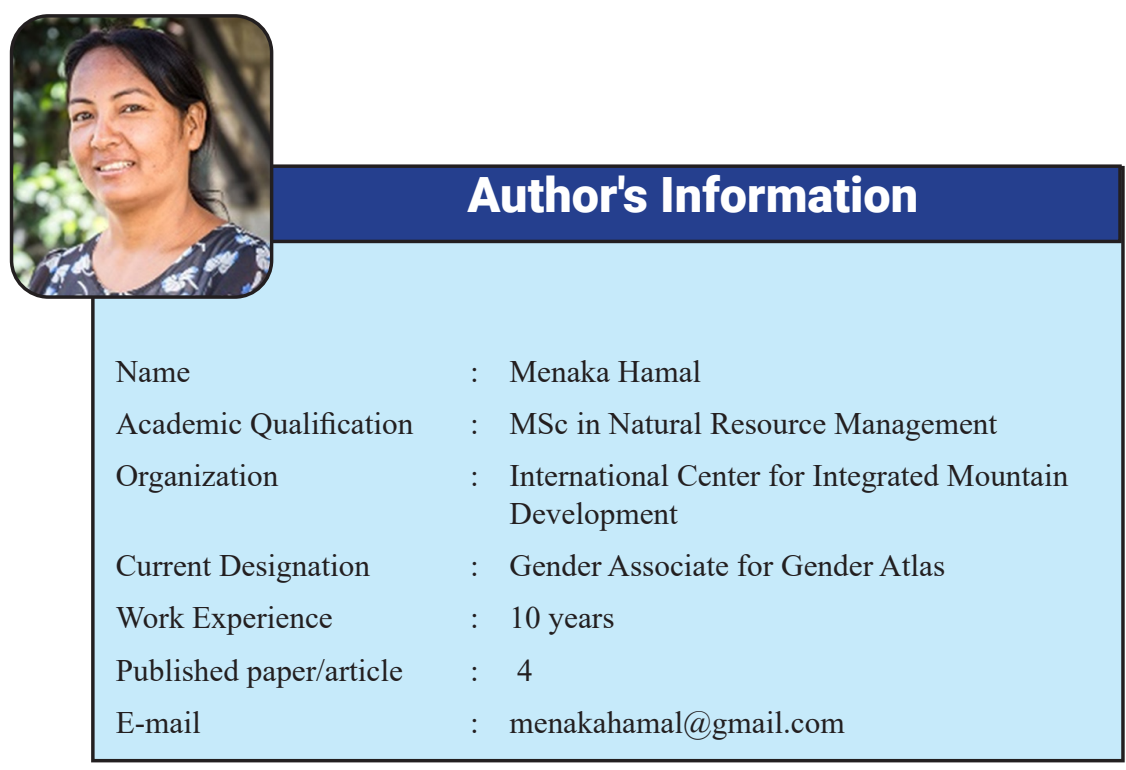

